\title{
Changing Scenario of Family System in India: An Analysis Against the Backdrop of Changing Social Values
}

\section{Karunanithi Gopalakrishan}

Formerly Professor of Sociology, Vellore Institute of Technology, Vellore, Tamil Nadu, India

Corresponding author: karunanithig@gmail.com (ORCID ID: 0000-0002-3631-295X)

Received: 23-10-2020

Revised: $11-01-2021$

Accepted: 28-02-2021

\begin{abstract}
The predominant type of living arrangement in pre-independence India was joint family system. It was based on the notion of collectivism and charity. It was a serving place for not only nurturing and preserving social values, but also passing them down through generations. After the advent of industrialization and subsequent emergence of urbanization and modernization, the joint families started disintegrating into nuclear families. The modern nuclear family is perpetually promoting the principle of individualism or independence in contrast to the value of collectivism deep-rooted in joint family. It is, therefore, a value shift in family from collectivism to individualism. It is followed by a loyalty shift in family from lineal ties to conjugal ties. Consequently, nuclear family has become an indispensible social unit in contemporary Indian society. However, its sustainability may perhaps be uncertain in a distant future because of the inclination of present younger generation to complete independence in life. Probably this may result in the emergent of a new type of living arrangement to satisfy the needs of generations of people in a remote future.

\section{Highlights}

(0 Views of Indian as well as foreign scholars on transition of Joint Family.

( Nuclear family as an inevitable alternate social unit in contemporary Indian society.

(0 Probability of uncertainties of nuclear family in distant future and the likelihood of emerging a new type of living arrangement suitable to future generations.
\end{abstract}

Keywords: Joint Family, Nuclear Family, Collectivism, Individualism, Values, Partner relationship

Family is considered to be the most essential part for everyone to lead a personal life. Every individual is taught about the importance of family since his/her childhood. In contemporary time, family across the world is undergoing changes in terms of its structure as well function. Similarly, the changes in joint family system in India took place in the first half of twentieth century though this was in existence since ancient time. This has resulted in the emergence of the nuclear family system. Joint family left an emotional bond between two generations, which kept its members united in all situations. The tradition and culture was passed on through generations, which made them uphold 'collectivism' as a predominant social value in their life. On the contrary, 'individualism' is much sought-after principle by the freedom loving couples in the nuclear family.

How to cite this article: Gopalakrishan, K. (2021). Changing Scenario of Family System in India: An Analysis Against the Backdrop of Changing Social Values. Int. J. Soc. Sci., 10(01): 51-62.

Source of Support: None; Conflict of Interest: None 
This paper aims at analyzing the views of Indian as well as foreign scholars on transition of Joint Family. It also attempts to establish nuclear family as an inevitable alternate social unit in contemporary Indian society. Finally it examines the probability of uncertainties concerning nuclear family in distant future and the likelihood of emerging a new type of living arrangement suitable to future generations.

\section{Methodology}

The methodology used mainly includes two qualitative tools to collect data: Case Study and Focus Group Discussion (FGD). Elaborate interviews were conducted with selective individuals through video conferencing due to the extending trend of the COVID-19 in India. Besides, a FGD was held with a mixed group of couples with the help of the same device. In addition to this, literature review forms a part of methodology by which several reviews of relevant published articles and books were done in order to prepare a conceptual foundation for the paper. One of the major limitations of the paper is that it confines its discussion on changing family system with reference to Indian society due to spatial constraint. The other one is that it limits it scope only to qualitative analysis based on data collected through a few case studies and a FGD, but it does not expand its scope to analyse quantitatively with a set of data from a sample population due to prolonged lockdown in India due to COVID 19 since March 2020.

\section{Joint Family}

\section{It is a traditional family system in India}

The two distinct features of Indian society are caste system and joint family system. Prabhu (1940, p. 217) holds the view that the traditional Hindu family was primarily joint in nature. It represented the value of collectivism (shared efforts and responsibilities) as its foundation. Hui and Triandis (1985, pp. 131-52) define collectivism as "a sense of harmony, interdependence and concern for others". The joint family members were engaged in their traditional occupation collectively with mutual cooperation. It included three to four living generations in the same house. They constituted a number of family units that were accommodated in separate rooms within the same house. They ate food prepared in a common kitchen besides sharing common property and wealth. They had strong kinship ties, which made them solid in cooperation and in all collective endeavors. They worshiped same idols with ritual performances and celebrated religious festivals together. Of the social scientists who defined joint family, Iravati Karve's (1965, p. 8) definition is comprehensive and precise: “A joint family is a group of people who generally live under one roof, who eat food cooked at one hearth, who hold property in common and who participate in common worship and are related to each other as some particular type of kindred". Agarwala (1962, pp. 141-43) points out that a specific authority structure is an essential feature of joint family in which the members are under the authority of an elder member relating to family matters. Therefore, it is compared with a giant banyan tree, whose branches grow roots which in turn support and feed the main trunk.

The joint family system was considered as "a way of life" by the Hindus. It was also considered as a sacred social institution where Sanatana Dharma ("the eternal law") was practiced. As it continued down through millennia (Bina Gupta, 1994, pp. 37-60), it was meant to be a symbol of the Hindu culture deeply rooted in the Hindu heritage. It insured not only the biological continuity through descending generations, but also the cultural continuity of Indian society. It preserved culture, customs, tradition, beliefs and values and passed them down through generations. In one way or another, the distinctiveness of Indian culture was kept in the age-old tradition of the joint family system. Its members were publicly known more by their family identity than by their individual identity. Thus, their family reputation brought them a status in the community. The social security, both material and psychological, provided by the joint family was unique and invaluable. For instance, Chekki (1996, pp. 409-413) points out that the joint family had taken care of old age members, widows, never-married adults and disabled. It also assisted unemployed members and provided them with security and support. 
The foundation of joint family rested on its two unique features: (i) its members had a sense of belongingness to the family and upheld the virtue of collectivity to achieve common goals, and (ii) it was laid on a motto: "one for all and all for one", which means that every member worked for the benefit of all members and all of them as a group worked for the benefit of each one. Mandebaum (1972, p. 41) notes that the members had a chance to learn the fundamentals of their culture and society from the joint family. Therefore, their life experience was rooted in their intra-family relations. Their strong unity at family level gave way to social solidarity and sociability. The family unity was accomplished by the members by following discipline in their behaviors and activities. Some of the important features of joint family included adjustment, cooperation, loyalty, concern for others and obedience. Of them, obedience was an essential protocol in intra-family relations. For instance, youngsters respected elders, addressed them in a dignified way, and sought their advice before taking important decisions. Psychologically, the family members felt an emotional interdependence, especially in terms of sharing their joys and sorrows with one another.

The kartha (head) of the family was usually an eldest son of aged parents. He was a privileged person as compared to all other members because he was given the right to offer pinda (funeral cake) at the time of sraddha ceremony (a ritual observance on the death anniversary of ancestors). He took decisions on socioeconomic matters of family besides administering its functions. However, he used to consult with his parents while deciding on crucial family matters. He had the responsibility of pooling the family income flowing from different sources including the earnings of all other members and of spending that money to cater to the needs of all members. Being a family head, he earned loyalty exhibited by his younger brothers, their wives and children. As he was the central figure of the family, he remained to be a symbol of integrity and generosity. Similarly, his wife by virtue had a privilege to exercise control over domestic affairs, especially cooking and celebrating religious festivals or ceremonies.

However, there were some variations in the joint family system in India with respect to geographical area, caste and the like. For instance, in Kerala State, the term tharavad refers to an ancestral home of Nair and a few other castes because it was the common home for the joint family system (Wikipedia). Nevertheless, the sleeping quarters of couples with their children were separate within the same house. Particularly the tharavad was a focal point in Nair community, in which the married women with their children used to live with their mothers. The husbands of those women used to live in the house of their mothers and happened to be occasional visitors to their wives and children. But now this family system has lost this unique feature.

Niranjan, Saritha and Roy (2005, pp. 623-651) report that there are two types of joint family system in India: lineally extended and collaterally extended joint families. The former includes head and his spouse with married son(s)/daughter(s) and their spouses and parents with or without other unmarried relative(s). The latter includes head and his spouse with married brother(s)/sister(s) and their spouses with or without other relative(s) including married relative(s). These families may possess divided or undivided properties. Each family has at least two generations living in close physical proximity or in far of places, but they would come together during important functions or specific religious ceremonies held in their ancestral home. This seems that they are structurally divided, but functionally united.

Generally most of the joint families were engaged in their traditional occupations, but some of them used to do non-traditional occupations depending upon situations. Nevertheless, it was a practice on the part of kartha to assign the work divisions to all members, except children, handicaps and aged according to their age and physical ability. Similarly, his wife was assigned to take care of domestic work. She used to consult with her daughters-in-law and wives of younger brothers of her husband relating to culinary aspect, housekeeping, gardening and the like. At the time of religious ceremonies, she assisted her husband while performing rituals and offering prayers along with other members. All members had the responsibility of extending support collectively with respect to all family endeavors. Usually male members had more authority than female 
members had, but Gore (1965, pp. 209-231) observes that elders had greater authority than youngsters had. According to him, their age not sex determined their authority in the family. This sort of family system was common among the Hindus probably until the first half of twentieth century. However, there were certain undeniable drawbacks of joint family system. Major drawbacks include lack of privacy among members; restricted freedom to express their views; unilateral decision by head particularly on financial matters; absence of individuality due to family protocol; gender inequality and the like.

\section{It is a place for nurturing and preserving social values}

Joint family served as a resourceful place for nurturing and preserving social values. It was inculcating those values in its members over centuries. As a result of this, they acquired the value of sharing knowledge, joys and sorrows, mutual adjustment and obligations, selfless support and solidarity. They came to understand through these values that "sharing is caring". For instance, someone wants to share food with some other person because he doesn't want that person to suffer from hungry.

Now many middle age and elderly people cherish their past pleasant days spent in joint families. For instance, a middle aged bank manager from a city in neighboring Andra Pradesh State in India has explained his childhood experiences with his grandparents as follows:

I grew up in a joint family with my parents, grandparents, cousins, aunts and their children and enjoyed their love and affection. My grandparents spent most of their time with all children including me. They used to impart values to us with interesting illustrations from religious texts. They were kind to listen to what I was trying to say during my childhood and answer to my queries patiently. Therefore I used to share my joys and sorrow mostly with them and also with my parents. Their nearness and affectionate inquiry were great relief to me when I fell ill in several occasions. They taught us to share whatever we had among us. Still I follow this value in terms of sharing my lunch with my colleagues. While attending to school homework in the evenings, my grandmother used to sit with me quite often as a stress reliever and to encourage me to complete the work. Unlike my grandparents, my wife and I are not able to be with our grandchildren because they are in a far of place with their parents. As their annual visit falls in summer, I usually avoid all other commitments and get ready to entertain them during their stay with us. They are also fond of being with us and enjoying our company.

Like children, the adult members in joint families had a number of occasions to learn values such as a sense of concern for others, kindness, adjustment, adaptability, cooperation, tolerance and the like. During a personal interview with an aged widow from a village in Tamil Nadu State in India, she shared her joint family experiences with respect to some of these virtues as follows:

I was 24 years old when I married to an eldest son from a rural joint family and gave birth to two children. Subsequently his three younger brothers married to educated women unlike me. Though their wives were much younger to me, they joined me willingly to attend to domestic as well as agricultural work. At one stage, our family size became large by their successive procreation. Though we came from different families located at different places and had differences of opinions, we could adjust with each other and share household responsibilities with a sense of collective spirit and cooperation. Since our aged widowed mother-in-law was mostly busy with organising and supervising women labourers engaged in agricultural operations, she did not interfere in our domestic work. However, I was keen on consulting with her and also with my counterparts before taking decisions on domestic affairs.

Since I was senior to them, they respected me. But they were not reluctant to remind me of my unnoticed mistakes related to domestic affairs. In fact that helped me several times avoid serious problems in our family. Sometimes, I used to be tough with, if they were careless while attending domestic work. But they tolerantly realized it without a sense of retaliation. As we were interacting as sisters, we used to discuss our personal problems and workout solutions while dining together in the late evenings. Particularly, when they had problems with their husbands, I tried to solve them with the help of my husband. After experiencing the joy of joint living for about a quarter century, we shifted to nuclear families in separate 
houses within our village due to the partition of common properties. However, often we used to visit each other and keep our kinship ties.

Moreover, other universal values such as respecting elders, charity and hospitality were very much associated with the joint family. The twin values, charity and hospitality, were greatly valued by joint family members. Several philanthropists from wealthy joint families in pre- as well as post-independence India used to contribute more money for charitable and religious activities and also help poor and needy. Besides, the joint family system was fostering unmotivated and selfless hospitality ever since it had become a profound household dharma ("path of rightness" for family members) in Indian society. This is an important value deep-seated in Indian culture, which was passed down through generations lived in joint families. During an in-depth interview with an elderly woman from northeastern part of Tamil Nadu State, she explained as follows:

For a period of 17 years from 1958 to 1975, I was living in a joint family with my husband, my two children, his brother's family with a child, his unmarried sister and aged in-laws. All of us were accommodated in a fairly big house in our village. Almost every day, we used to provide food prepared by us to 4-6 persons including relatives, friends, visitors and strangers in and around the village. Especially in festival times, large quantity of food prepared by professional cooks was served to many guests visiting us on invitation besides providing food to a large group of hungry people all over the day. On several occasions, we used to cook food even after lunch or dinner to feed the belated guests. Every day my father-in-law was keen on inviting at least one or two local friends to join him for lunch. It was rare to see him taking lunch alone. In the same way and with the same spirit, on many special occasions, we were invited by our relatives and friends in joint families for a get together over lunch. Since our family was depending on large scale cultivation, we were able to continue this hospitality as a core value until 1975. After the partition of common properties in the same year, my husband shifted me and my children to Chennai, capital of Tamil Nadu State, owing to his employment and our children's education. Since then we have been living in nuclear family. But now, at my age of 80, I hardly see such sort of hospitality in the present generation of people living nuclear families.

Elders, particularly grandparents, used to impart values and morals in their grandchildren by narrating moral stories, thereby systematically promoting discipline among them. Their advices and suggestions guided youngsters in family while discharging their household duties and taking crucial decisions in life. In return, they earned respect from the youngsters. Besides, children relished an unconditional love expressed by other family members that was, in turn, reciprocated by the former. Needless to say the values and customs were passed down through generations of joint family members over centuries.

\section{Mixed views of scholars on transition of joint family}

Some scholars such as Goode (1968) and Rao, Kulkarni \& Hanumantha (1986) mention that joint family was never a dominant type of family, but all types of families (joint, nuclear, single and other) existed in India at the same point in time. This may be true, but the fact is that, over centuries a large majority of the Hindus were living in joint family system. Hence the Indian society was predominantly characterized by this family until the first quarter of twentieth century, i.e., before the advent of industrialization in India. Afterwards the joint families started disintegrating into nuclear families to the extent that the latter get proliferated extensively in the contemporary Indian society.

J.P. Singh, (2004, pp. 129-166) points out that, in the current scenario, the joint families are disappearing in rural India too. This transition greatly owes to ruralurban migration of sons from joint families in pursuit of education or in search of jobs or in making out an earning from non-traditional occupations. In some cases, regardless of undivided common properties, married sons of same parents have deliberately settled in nuclear families because of their inclination to an independent life. Thus, the joint families have given way to increasing number of nuclear families across India. This is evident from the census of India that, on the whole, there is an increase in the nuclear households from 51.7 per cent in the 2001 census to 52.1 per cent in the 2011 census (Census of India, $2001 \&$ 2011). At the present, most of 
the existing nuclear families in urban areas are believed to be the offshoots of rural joint families.

On the one hand, contrary to the presumption that the proportion of nuclear families in urban areas is significantly higher than the proportion of similar families in rural areas, the data released by the Central Government in July 2017 show that the proportion of nuclear families has dropped in urban areas, where the people choose to live in extended families. On the other hand, in rural areas, there is a great sign of fragmentation of joint families into nuclear families. The increasing number of nuclear families and decreasing number of joint families is at a faster pace in rural than urban areas (Zeeshan Shaikh, 2017).

An emerging trend in urban areas is that many nuclear families of disintegrated joint families are forced to stay together due to lack of adequate housing. They become "supplemented nuclear families", which include head and spouse with or without unmarried children, but with other relatives without spouses. What is striking here is the decreasing proportion of nuclear families in urban areas, i.e. in 2001, the proportion of nuclear families has decreased from 54.3 to 52.3. In contrast, in rural areas, the proportion of nuclear families has increased from 50.7 to 52.1. In the meantime, the proportion of joint families across India is declined significantly from 19.1 to 16.1. However, the decrease in proportion of joint families was sharper (from 20.1 to 16.8) in rural areas than it was (from 16.5 to $14.6 \mathrm{t}$ ) in urban areas (Zeeshan Shaikh, 2017).

Besides this rural-urban differences with respect to the proportion of joint and nuclear families, some earlier Indian scholars hold more or less a similar view on the status of joint family system in India. For instance, Kapadia (1956) states that the migrant families in cities still sustain their ties with their joint families in villages and continue to preserve their "joint family ethics". Srinivas (1969, p. 72) claims that the decrease in the number of joint families in urban areas does not mean that they are breaking down. Shah (1998, pp. 6-7) sees that the entire urban society is not moving against the norms of joint household. Similarly, Gore (1968) and Gupta (1978) consider that the joint families are undergoing changes rather than breaking down.
Some other earlier Indian scholars such as Dube (1955), Desai (1964) and Madan (1965) have adopted "development cycle" approach to study the family changes in India. According to them, family is to be understood as a process that undergoes cyclical changes due to fission and fusion. In other words, family structure keeps on changing in a cyclical fashion: "expanding" from nuclear to joint through marriage and birth and "contracting" from joint to nuclear through death and partition. In a similar way, Mullatti (1995, pp. 11-25) states that, as situations change from time to time, a nuclear family turns into a joint family and a joint family into a nuclear family owing to the cyclical changes. Kapadia (1966) presents his view that even if a traditional joint family breaks into nuclear families, these nuclear units would become modified joint families. In other words, joint family breaks structurally, but its individual units continue to form parts of joint family in terms of functions and sentiments.

In some studies, preference of people for joint family is confirmed by foreign scholars such as Ames (1969, pp. 1217-1224), Khatri (1975, pp. 633-642) and Conklin (1976a \& 1976b, pp. 771-779). Similarly, district-wise analysis of selected states in India by Kolenda and Haddon (1987) shows that an increase in the number of joint families in the districts depends on an increase of Hindu population in those districts. This confirms that the Hindus lived mostly in joint families. In a study conducted in Karnataka, Caldwell et al. (1984, pp. 215229 ) find that the joint families were common among households with some agricultural lands. In support of this, Niranjan et al. (2005, pp.623-651), in a nation-wide study, establish that the joint living in a family depends on its standard of living as well as agricultural land owning status.

Some of the Indian as well as foreign scholars explain the relationship between joint family system and caste system in India. For instance, Gough (1956, pp. 826853), Kapadia (1956: pp. 111-126), Bernard Cohn (1961, pp. 1051-1055), Madan (1965), Kolenda (1968), Shah (1968, pp. 127-135), Caldwell et al. (1984, pp. 215-229), and Srivastava and Nauriyal (1993, 159-163) disclose that higher caste people tend to form joint families, whereas the lower caste people (basically landless 
agricultural laborers) are inclined to nuclear families. In contrast, Niranjan et al. (2005, pp. 623-651) claim that caste alone is not a determinant of joint family, but its economic as well as land owing status weigh more than other factors. Though they support the view that the joint family system is continuing, they point out that, at the present, its proportion is significantly lower than the proportion of nuclear families. Further they note that there is a significant increase in the number of nuclear families in urban as well as in rural areas of India. Nevertheless, they observe, this increasing trend is relatively faster in urban than in rural areas. Further they find that in urban areas, more than a majority of families are nuclear and the rest of them constitute more or less equal proportions of joint and supplemented nuclear families. But, in rural areas, close to a majority of families are nuclear, whereas one-fourth of them are joint families and one-fifth of them are supplemented nuclear families. It is thus evident that there is a slight difference between rural and urban areas regarding the distribution of types of families.

Sinha (1984, pp. 271-286) mentions about "transitional families", which are under the same roof, but with separate kitchen, separate purse, considerable autonomy and reduced responsibility on the part of family members. According to him, such families are structurally nuclear, but they continue to function like joint family. This view is corroborated by the observations of Desai (1956, pp. 144-156), Kapadia (1956, pp. 111-126), Beteille (1964, pp. 237-244), Gore (1965, pp. 209-223), Singer (1968), Ames (1969, pp. 1217-1224), Khatri (1975), Kurian (1976), Ishwaran (1974), Singh (1988) and other such scholars.

Regardless of these mixed views of scholars on the transition of joint family, the wide prevalence of nuclear family system in contemporary Indian society is evident. The rapidly changing Indian society is in need of this family type as a suitable alternate. Therefore, it is argued in the following session as how the nuclear family system is compatible to the present Indian society?

\section{NUCLEAR FAMILY}

\section{Predominance of nuclear family against the backdrop of changing values}

After the advent of industrialization and subsequent emergent of urbanization in India, the increasing commercialism and decreasing humanism among people have overshadowed their generosity. Consequently this change has shifted their focus from collective interest (foundation of joint family) to self-interest (an important feature of nuclear family). This focus shift has been systematically facilitated by much preferred nuclear family. In urban areas, the migrant employees and workers living in nuclear families are independent of their joint family members living in rural areas. The former's inclination to individuality has decreased their collective interest and increased their self-interest to aim for more financial gains and personal benefits. Therefore, they tend to be aggressive in accumulating wealth as against their ancestors who lived a contented and peaceful life in joint families over centuries.

Besides, as elsewhere in the Western countries, the development of capitalism ushered by industrialization in India has made a great impact on people in terms of making them strive to attain economic development by getting access to available resources. Their propensity to accumulate wealth has made them prefer nuclear family to fulfill their needs. Driven by profit motive they have become idiosyncratic and greedy. Their greediness is perhaps enhanced by capitalist culture, which is easily adopted by the nuclear family. Therefore, Goode (1963, pp. 10-18) stresses that, for modern economic conditions, the nuclear family is more suitable than joint family. In support of his view, Freed and Freed (1982, pp. 189-202) claim that the nuclear family is suitable to the present labor market situations. In other words, expanding business enterprises associated with the existing labor market situation determine the type of family. Therefore, in a typical situation of increasing employment avenues, a great majority of educated young men and women tend to secure jobs elsewhere and settle down in nuclear families.

Importantly the mass consumption culture, a product of globalization, has largely influenced the working middle class people in urban areas of India. This culture like the capitalist culture has nurtured the habit of greediness in them to attain material well being to lead a comfortable life. It is needless to say that most of the working couples in nuclear families take efforts 
to multiply their earnings to meet their ever growing material needs. Their consumer behaviour never let them to remain satisfied with what they adequately possess, but makes them suffer from undue hunger for over-possession of goods. They do not mind to toil them to achieve their desired economic status. This driving spirit in most of the couples in nuclear families put them to work for hours together to accomplish their desire of material well being to lead a well-to-do life. But they have least concern for the well-being of their joint family members living in villages.

In urban areas, the working couples living in nuclear families exercise their freedom to work out plans to enhance their earnings as well as to advance their children's education to meet the needs of present employment market. Besides their regular work, they prefer to take secondary jobs at their convenience to boost up their family economy. Since their life becomes mechanical, they hardly find time to extend hospitality to their guests as compared to their joint family counterparts Moreover, for the same reason, their interaction with their children is inadequate. Unlike this, the joint family served as a basic unit to get the children socialized with culture, tradition and values. In addition to this, it served as an important agent of social control.

In urban areas, a majority of working couples in nuclear families want to be independent of each other in several aspects as against their joint family counterparts, who always confined to the value of collectivism supported by their value of mutual cooperation. This is, in a way, a value shift from collectivism to individualism. Though these two principles are dichotomous, they have been practiced simultaneously by the Hindus since ancient time. Nevertheless, they followed collectivism in some situations and individualism in some other situations. Most of the previous generations of people considered collectivism as an essential value both in private and public life, whereas the majority of youngsters in the present generation declare that individualism is a suitable principle to modern life style, as they want to think and act independently rather than depending on others. They strongly believe that this principle would result in development, innovation and anticipated changes in all areas of life. However, both the principles have advantages and limitations for the present generation of people.

Unlike the members of joint families, the working couples in nuclear families are keen on getting them satisfied by fulfilling their requirements because they are economically independent. They are more concerned with meeting their needs rather than supporting their aged parents financially. This seems that there is a value shift in terms of shifting their loyalty from lineal ties to conjugal ties. In support of this, Singh (2003, pp. 53-70) states that the disintegration of joint family is mainly due to career orientation of couples, their economic freedom, independent decision and focus on individual accomplishment.

The individualistic or independent mindset seems to have pronounced more amongst the couples employed in IT sector than their counterparts working in other sectors in India. For instance, during a personal interview, a newly married couple working in different multi-national IT companies in Bangalore city, capital of Karnataka state in India, jointly expressed their inclination to independence, which is very much associated with nuclear family system.

Both of us were born and brought up in nuclear families unlike our parents who lived in joint families for about thirty years right from their childhood. Both of our parents migrated to Bangalore city from Tamil Nadu State over a couple of decades ago due to their employment. After our graduation, we secured employment in different leading software companies in this city in 2014 and subsequently got married (love marriage) and settled in a nuclear family. Our choice of nuclear family mainly for freedom was also accepted by our parents. Now we are independent and free to do whatever we like. For instance, we have purchased a car out of our earnings. We have also decided to purchase a flat in a multistorey apartment by raising a bank loan and also to buy required furniture items and household appliances to make our home sufficiently equipped. We jointly meet all our household expenditures including house rent from our salary. However, we are economically independent and fulfilling our individual requirements without depending on each other. In the same way, we are independent of our personal savings and supporting our aged parents financially at times. We normally share our domestic work besides caring our little child with the 
support of a full time servant maid. Often we visit our parents and they also visit us occasionally.

The mutual understanding and adjustability between these spouses is not found among most of the couples in nuclear families. They have to necessarily depend on each other for certain things, no matter how much they are independent of each other. The tendency of couples in a nuclear family to total independence would create an unbridgeable gap between them. As a result of this, conflicts between spouses are bound to arise frequently. Eventually some conflicting couples may be driven to the extent of breaking up their marital bond. Therefore, in distant future, the stability of nuclear family is doubtful because of the couples' choice of total independence.

\section{Uncertainty of nuclear family in a remote future}

It is inferred from the preceding discussion that the nuclear family has become an alternate to joint family in contemporary Indian society, which is undergoing rapid changes in all areas of life including social values. Now it is a big question before us: will nuclear family be a sustainable social unit in a distant future? The answer is not as simple as 'yes' or 'no' because its sustainability seems to be uncertain or unpredictable after many generations from now. It may be due to their increasing tendency to complete freedom in life. This tendency may perhaps be facilitated by changing life style from generation to generation of people living in nuclear families. It may change their attitude to family and marriage to the extent that they prefer to live alone or to lead a conjugal life through "live in relations". Consequently, they may tend to modify the norms of family and marriage flexibly in order to suit to their changing life-style.

Their tendency to complete independence to lead a life as they like may be due to two important reasons: one is that they may like to be free from parental control and family responsibilities to decide on anything according to their likings and the other one is that they may wish to exercise their freedom to secure a living arrangement temporarily or permanently by choosing agreeable partners without marriage. This sort of arrangement (termed as "live in relations" or "partner relations"), an alternate to legal marriage, has become increasingly common in Western countries since the late 20th century. Couples in this transitory relationship may not be able to constitute stable families. After studying family situation in Europe, Dolors Comas-d'Argemir, (2007) observes: "In the last few decades, family has experienced a true revolution: a decline in marriage and an increase in informal relationships, fragile marital relations, the development of single parent and step families, and new homoparental families". The decline in marriage rate in Europe has resulted in the emergence of nonconventional living arrangements such as "living apart together" and "weekend-relationships" (OECD, p.34). In Europe, the wide spreading "living apart together" means that a partner while staying in parental home has sexual relationship with an opposite sex partner living alone or looking for a new relationship after divorce. Sometimes both of them live together during weekends ("weekend-relationships"), but avoid becoming stable couples. This living arrangement may not let them to constitute a stable nuclear family.

Though this is an unusual phenomenon in contemporary India, some employed men and women in cosmopolitan cities seem to have chosen "live in relations". Since there is no specific law in India with respect to this sort of living arrangement, it is not "illegal" in the eyes of law. The Indian judiciary is neither encouraging explicitly nor prohibiting this relationship. However, once it is legalized, it is expected to decrease the number of legal marriages and multiply couples in quest of "live in relations". This type of eccentric and transitory living arrangement may likely to degrade family system. Hence the stability of nuclear family may perhaps be uncertain or unpredictable in a remote future.

After experiencing remarkable changes in life, many aged couples in the present generation, who lived in joint families for several decades, want their sons and grandchildren to live in nuclear families considering their propensity to independence. According to them, it is discomfortable for young, educated, career oriented and freedom loving people to lead a connubial life along with their parents, brothers and sisters. In the same way, most of the young and educated couples strongly feel that conjugality is something to do with the freedom bind personal life without the interference 
of their family members. Even if the egos of a couple do not compromise with each other in certain aspects, they prefer to live in nuclear family for independence.

In modern times, a significant proportion of working couples living in nuclear families are not able to get along well with each other due to frequent clash of their egos. This is highly pronounced among couples employed in IT companies. While conversing with a Family Court Judge from High Court in Chennai city in Tamil Nadu State, he mentioned that over three-fourths of divorce cases registered in his court were filed by young couples employed in software companies. Incidentally most of them were living in nuclear families. He also specified that besides other reasons, ego conflict between the spouses is the predominant cause of this problem. Since both of them get lucrative salary and experience equal work status, they want to be independent of each other in several aspects and like to enjoy equal rights. The conflict between them will arise when one interferes in the freedom of other. In support of this, Comasd'Argemir (2007) finds that the individuality and equality along with economic independence of women has resulted in a contradiction between these ideologies on the one hand and the dynamics of domestic life on the other.

This contradiction is an alarming stress factor for both spouses. It is a major cause of frequent marital conflict, which eventually results in dissolution of marriage bond. During an interview, a married woman employee from a software company in Chennai city has explained reasons for her decision to obtain divorce as follows:

I am 27 years old and married to a 30 years old man of the same software profession. Ours was an arranged marriage. We settled down in a nuclear family in Chennai in 2017. I have been an independent person right from my school days, as my parents never restricted my freedom in my endeavours including my studies and employment. But, at the same time, they imparted values and morals in me to refine my behaviors and activities. Initially I believed that my husband would not interfere in my freedom and treat me with the egalitarian value. But within a few months of our conjugal life, I came to know that he is an ego-centric and a male chauvinist expecting me to follow whatever he says. I had the first shock when he demanded me to give him my savings in a bank and its debit card. But I could not yield to his demand and firmly told him that I don't want to lose my financial freedom. However, I agreed to contribute my share to meet monthly expenses of family including house rent. But he did not accept, as he wanted to have complete control over my earnings. Besides, he was reluctant to share our domestic and allied work. When I engaged a maid servant to assist me in attending to household chores, he categorically warned me to pay her from my purse. Even after experiencing these hardships, I believe that nuclear family is a safer matrimonial home for a woman provided her partner treats her equally with a mutual understanding.

After some days, one morning he forced me again to handover my savings along with the bank debit card. When I bluntly refused, he had beaten me repeatedly and left for work immediately. That day, after applying leave for a week, I left my office in the evening to meet my parents residing in a nearby sub-urban area. After an elaborate consultation with them in the presence of our family lawyer, I expressed my decision to divorce him. After the approval of my parents, I filed a case against him to obtain divorce and subsequently informed him of this through my friend. Next day I deliberately avoided his repeated calls over mobile and refused to meet him when he called for a meeting. Meanwhile I fixed a rental flat in an apartment close to my company and started living there with the support of my parents. At last I got my legal separation paper after a couple of years.

This sort of trend in different forms may also be prevailing amongst many young couples employed in other sectors in India. Unlike the joint family members who remained to be trustful and helpful to each other, the egos of working couples in nuclear families have often led them to be uncompromising persons. In the absence of elders' advice and guidance, their unquestionable freedom in their behaviors and activities remains to be inimical. But, in the worst-case, they resort to free them from their marital bond. That is perhaps the reason why, a section of working couples in India tend to prefer conjugal union without marital bond for the reason that they can simply come out of this union, if they do not get along well. Therefore, it is presumed that, in a distant future, a considerable proportion of youngsters may choose to adapt a living arrangement to lead a conjugal 
life outside marriage ambit. In this situation, the nuclear family as it exists now may not cope with the changing conjugal relationships after several generations and may become unstable because of its incompatibility at that point in time.

\section{CONCLUSION}

World over the changes taking place in family system are inevitable. Likewise, the changes in joint family system in India took place in the first half of twentieth century. Consequently joint family was replaced by nuclear family. This change primarily owes to industrialization and subsequent emergent of urbanization that influenced a shift from collectivism as a value to individualism as a principle. This led to a shift from collective interest to self-interest. Eventually this resulted in a shift of loyalty as a value from lineal ties to conjugal ties. Besides, a great impact of globalization on family has been the development of consumer culture. For instance, the consumer behavior of working couples in nuclear families never let them to remain satisfied with what they adequately possess, but it has made them suffer from too much of hunger for over-possession of goods. This has turned them to be greedy to accumulate wealth to meet their ever growing material needs. But they are hardly concerned about the well-being of their joint family members living in villages.

The increasing tendency of couples in nuclear families to total independence in life may likely to pose a threat to the sustainability of nuclear family in a distant future. This tendency may perhaps change their attitude to family and marriage to the extent that they prefer to live alone or choose to lead a conjugal life outside marriage. Consequently, they may tend to modify the norms of family and marriage flexibly in order to suit to their changing life style. As a result of this, an increasing number of them may likely to prefer "live in relations" after some generations from now. The nuclear family as it exists now may not cope with this eccentric and transitory living arrangement. It may likely to degrade family system in a remote future and eventually make it unstable because of its unsuitability at that point in time.

\section{REFERENCES}

Agarwala, B.R. 1962. 'Nature and extent of social change in a mobile commercial community (Study of change in family and Marriage Patterns).' Sociolo. Bul., 4(2): 141-143.

Ames, M.M. 1969. 'Modernization and social structure: Family, caste and class in Jamshedpur.' EPW., 4 (28, 29 \& 30): 1217, $1219,1221,1223-1224$.

Beteille, Andre. 1964. 'Family and Social Change in India and other South Asian Countries.' EPW., 16 (5, 6 \& 7), 237-244.

Caldwell, J.C., Reddy, P.H. and Caldwell, P. 1984. The determinants of family structure in rural South India. J. Marriage and the Family, 46(1): 215-229.

Census of India, 2001 \& 2011.

Chekki, D.A. 1996. 'Family values and family change.' J. Comparative Family Stu., 27(2): 409-413.

Cohn, Bernard. 1961. 'Chamar family in a North Indian village: a structural contingent.' EPW., 13(27, 28 \& 29): 1051-1055.

Comas-d'Argemir, Dolors. 2007. 'Family today: individuality and public policies.' Wellchi Working Paper Series No. 7. Barcelona: CIIMU - Institute of Childhood and Urban World.

Conklin, G.H. 1976a. 'Family structure, caste and economic development.' In Family and social change in modern India, edited by G. R. Gupta, New Delhi: Vikas Publishing House.

. 1976b. 'The household in urban India.' Journal of Marriage and the Family, 38(4): 771-779.

Desai, I.P. 1956. 'The joint family in India: An analysis.' Sociological Bulletin, 5(2): 144-156.

. 1964. Some aspects of family in Mahua. Bombay, Asia Publishing House.

Doing Better for Families. 2011. Organization for Economic Cooperation and Development (OECD): 24.

Dube, S.C. 1955. Indian village. London: Routledge.

Freed, Stanley. A. and Freed, Ruth. S. 1982. Changing family types in India. Ethnology, 21(3): 189-202.

Goode, W.J. 1963. World Revolutions and Family pattern. New York: The Free Press.

1968. Foreword in Urbanization and Family Change, M.S. Gore. Bombay: Popular Prakashan.

Gore, M.S. 1965. 'The Traditional Indian Family.' In Comparatives Family System' edited by N.F. Nimkoff, 209-223. Boston: Houghton Miffin.

1968. Urbanization and family change. Bombay: Popular Prakashan.

Gough, E. Kathleen. 1956. 'Brahman kinship in a Tamil Village.' Am. Anthropologist, 58(5): 826-853. 
Gupta, Bina. 1994. 'Modernity and the Hindu joint family system: A problematic interaction.' Int. J. World Peace, 11(4): 37-60.

Gupta, G.R. 1978. 'The family in India: The joint family. In The Family in Asia,' edited by M.S. Das and P.D. Bardis. New Delhi: Vikas Publishing House.

Hui, C.H. and Triandis, H.C. 1985. Measurement in CrossCultural Psychology: A Review and Comparison of Strategies. J. Cross-Cultural Psychology, 16(2): 131-152.

Ishwaran, K. 1974. 'Interdependence of the elementary and extended family.' In the Family in India: A Regional View, edited by George Kurian, 163-178. Paris: Mouton, The Hague.

Kapadia, K.M. 1956. 'Rural family patterns: A study in urbanrural relations.' Sociological Bulletin, 5(2): 111-126.

1966. Marriage and family in India. $3^{\text {rd }}$ ed. Bombay: Oxford University Press.

Karve, Irawati. 1965. Kinship Organization in India. $2^{\text {nd }}$ ed. Bombay: Asia publishing House, p.8.

Khatri A.A. 1975. 'The adaptive extended family in India today.' J. Marriage and the Family, 37(3): 633-642.

Kolenda, Pauline. 1968. 'Region, caste and family structure: a comparative study of the Indian joint family.' In Structure and change in Indian society, edited by Milton Singer and Bernard S. Cohn, 339-396. Chicago: Aldine.

Kolenda, P. and Lorraine, H. 1987. 'Marked Regional Differences in Family Structure in India.' In Regional differences in family structure in India, edited by Pauline Kolenda. Jaipur: Rawat Publications.

Kurian, G. 1976. 'The Indian Family in transition: some regional variations', In Family and social change in modern India, edited by G.R. Gupta. New Delhi: Vikas Publishing House.

Madan, T.N. 1965. Family and kinship: A study of the Pandits of rural Kashmir. Bombay: Asia Publishing House.

Mandebaum, D.G. 1972. Society in India: Change and Continuity, 2 vols. Bombay: Popular Prakashan, p.41.

Mullatti, L. 1995. Families in India: Beliefs and realities. J. Comparative Family Stu., 26(1): 11-25.

Niranjan, S., Saritha Nair. and Roy, T.K. 2005. 'A SocioDemographic Analysis of the Size and Structure of the Family in India.' J. Comparative Family Stu., 36(4): 623-651.
Prabhu, P.H. 1940. Hindu Social Organization. Bombay: Popular Prakhasan, pp. 217.

Rao, N.B., Kulkarni, P.M. and Hanumantha, R.P.1986. Determinants of fertility decline: A study of rural Karnataka. New Delhi: South Asian.

Shah, A.M. 1968. 'Changes in the Indian family: An examination of some assumptions.' EPW., 3 (1and 2): 127- 135.

Shaikh, Zeeshan. 2017, July 6. 'Rural India starts to go nuclear, urban families grow in shrinking space.' The Indian Express. Retrieved from https://www.indianexpress.com

1996. 'Is the joint household disintegrating?' Economic and Political Weekly 31 (9): 537-542. Doi: jstor.org/stable/4403861

1998. The family in India: Critical essays. New Delhi. Orient Longman, pp. 6-7.

Singer, Milton. 1968. The Indian Joint family in modern industry. In Structure and change in Indian society edited by Milton Singer and Bernard. S. Cohn, 423-454. Chicago: Aldine.

Singh, A.M. 1988. Female-headed household: an overview of the concept and his application to poverty alleviation. New Delhi: ILO.

Singh, J.P. 2003. 'Nuclearisation of Household and Family in Urban India.' Sociological Bul., 52(1): 53-70.

2004. The contemporary Indian family. In Handbook of World Families edited by B.N. Adams and J. Trost, 129-166. California: Sage Publications Inc.

Sinha, D. 1984. 'Some recent changes in Indian family and their implications for socialization.' Indian J. Soc. Work, 45(3): 271-286.

Srinivas, M.N. 1969. India: Social structure. New Delhi: Publications Division, pp. 72.

Srivastava, K.K. and Nauriyal, P.K. 1993. ‘Family structure and child survival among Jamsans of Uttar Pradesh.' Social Change, 23(2 and 3): 159-163.

Tharavad. (n.d). in Wikipedia. Retrieved September 15, 2019, from https://en.wikipedia.org/wiki/Tharavad 